\title{
ISÓTOPOS DE ESTRÔNCIO NO SÍTIO ARMAÇÃO DO SUL, FLORIANÓPOLIS/SC: RESULTADOS PARCIAIS, REFLEXÕES INICIAIS
}

\author{
Gabriela Oppitz ${ }^{1}$ \\ Paulo DeBlasis ${ }^{2}$ \\ Andrea Lessa ${ }^{3}$ \\ Veridiana T. S. Martins ${ }^{4}$ \\ Murilo Q. R. Bastos ${ }^{3}$ \\ Luciane Z. Scherer ${ }^{5}$ \\ Liliane A. Petronilho ${ }^{4}$
}

\section{RESUMO}

Por meio da determinação das razões isotópicas de estrôncio $\left({ }^{87} \mathrm{Sr} /{ }^{86} \mathrm{Sr}\right)$ presentes no esmalte dentário dos indivíduos sepultados no sítio Armação do Sul, procuramos compreender melhor as mudanças que ocorrem no sítio conchífero Armação do Sul (Florianópolis/SC) e no contexto maior de sambaquis do litoral catarinense a partir de 2.000 A.P. Os resultados das análises isotópicas, comparados a outros dados isotópicos gerados para o litoral catarinense (BASTOS, 2009; 2014) indicam que os processos de mudança possivelmente se desenrolaram diferentemente em porções litorâneas distintas do litoral catarinense e que, no caso do sítio Armação do Sul, as mudanças observadas podem estar relacionadas a uma maior circulação e incorporação de indivíduos de diferentes partes do litoral central.

Palavras-chave: Isótopos estáveis, Mudança, Sambaquis, Litoral catarinense.

Embora haja uma sintonia cronológica que aponta para um único processo de ocupação para o litoral norte (região da baía da Babitonga), litoral central (ilha de Santa Catarina e continente próximo) e litoral sul (região da paleolaguna de Santa Marta) de Santa Catarina, um olhar mais atento sobre os contextos arqueológicos das diferentes porções litorâneas permite entrever diferenças e particularidades que levam à ideia de processos de ocupação distintos, porém condicionados pelos mesmos eventos primordiais. Processos de ocupação que se interseccionam em determinados pontos no tempo e no espaço, porém que se desenrolam de forma desigual quanto à direção,

\footnotetext{
${ }^{1}$ Museu de Arqueologia e Etnologia, Universidade de São Paulo. E-mail: gabrielaoppitz@gmail.com.

${ }^{2}$ Museu de Arqueologia e Etnologia, Universidade de São Paulo.

${ }^{3}$ Museu Nacional, Universidade Federal do Rio de Janeiro.

${ }^{4}$ Instituto de Geociências, Universidade de São Paulo.

${ }^{5}$ Museu de Arqueologia e Etnologia, Universidade Federal de Santa Catarina.
} 
intensidade, atores envolvidos e outros elementos em cada um dos contextos.

Por volta de 2.000 e 1.500 A.P ocorre uma mudança aparentemente repentina nos padrões deposicionais dos sambaquis do litoral catarinense, período em que deixam de ser formados principalmente por conchas, passando a ser formados por um sedimento escuro com enorme quantidade de carvão e outros materiais orgânicos (DEBLASIS; GASPAR, 2008/2009). Apesar da variação composicional, nesta camada escura mantêm-se os processos construtivos associados às estruturas funerárias, bem como as características das indústrias líticas e óssea (DEBLASIS et al., 2007, p. 42). No momento seguinte, a partir de 1.500 A.P., começa a aparecer cerâmica nos horizontes superficiais de alguns sambaquis e em sítios conchíferos rasos, cerâmica esta que costuma ser atribuída a grupos da família linguística Jê e que vem acompanhada por algumas mudanças em conteúdo e estratigrafia que, contudo, não parecem constituir uma ruptura ou mudança estrutural absoluta.

O sítio conchífero da Armação do Sul (Florianópolis/SC) apresenta poucas conchas em sua composição, representando esse momento mais tardio, e, além disso, apresenta uma mudança própria no padrão deposicional, com uma estratigrafia que vai de areia marrom clara para terra preta. Embora as características da indústria óssea e lítica nas diferentes camadas permaneçam as mesmas, tal continuidade não é observável nas práticas mortuárias que, acompanhando a mudança no padrão deposicional, vão de sepultamentos envoltos em ocre e com muitos adornos como acompanhamento funerário para sepultamentos sem ocre e com poucos adornos, porém com muitas pontas ósseas. Assim, o sítio Armação o Sul incorpora algumas continuidades e descontinuidades dos sítios do litoral catarinense, mostrando-se sintonizado com aquilo que estava acontecendo em nível regional, e, ao mesmo tempo, apresenta características particulares que remetem àquelas relações que estavam sendo empreendidas em nível local.

A análise das razões isotópicas de diversos elementos químicos estáveis tem se mostrado uma importante ferramenta para a resolução de problemas arqueológicos relacionados à proveniência e paleodieta das populações do passado, bem como ao paleoambiente em que essas populações viveram. Para o estudo de migração e mobilidade humana, é a análise da razão entre dois isótopos do elemento estrôncio, ${ }^{87} \mathrm{Sr}$ $\mathrm{e}^{86} \mathrm{Sr}$, que vem gerando resultados mais interessantes. 
Neste trabalho serão apresentados os resultados parciais das análises isotópicas de estrôncio $\left({ }^{87} \mathrm{Sr} /{ }^{86} \mathrm{Sr}\right)$ feitas a partir do esmalte dentário dos indivíduos sepultados no sítio Armação do Sul, realizadas no laboratório do Centro de Pesquisas Geocronológicas da Universidade de São Paulo (CPGeo/USP). As análises foram empreendidas no intuito de compreender melhor as mudanças que ocorrem no sítio em questão e nos demais sítios conchíferos do litoral catarinense a partir de 2.000 A.P., buscando entrever se as mudanças observadas podem ou não estar relacionadas à incorporação de indivíduos não locais, provenientes do interior ou de outras regiões litorâneas, por essas populações.

\section{O SÍTIO ARMAÇÃO DO SUL}

Situado em praia de mesmo nome na porção sul da Ilha de Santa Catarina, o sítio Armação do Sul foi escavado por João Alfredo Rohr em duas etapas, uma em 1969, com a participação de Margarida Andreatta e publicação de nota prévia (ROHR; ANDREATTA, 1969), e outra em 1974, cujos resultados foram publicados no jornal Correio do Povo, de Porto Alegre (ROHR, 1974). Com base no diário de campo de Rohr, perfis, plantas e fotografias geradas ao longo da pesquisa, a equipe do Instituto Anchietano de Pesquisas realizou a curadoria e o estudo posterior do material do sítio situado no Museu do Homem do Sambaqui "Pe. João Alfredo Rohr, S.J.”, no Colégio Catarinense -, publicando os dados das escavações, o resultado das análises e demais interpretações desenvolvidas em Schmitz et al. (1992). 
Figura 1. Localização do sítio da Armação do Sul, na Ilha de Santa Catarina.

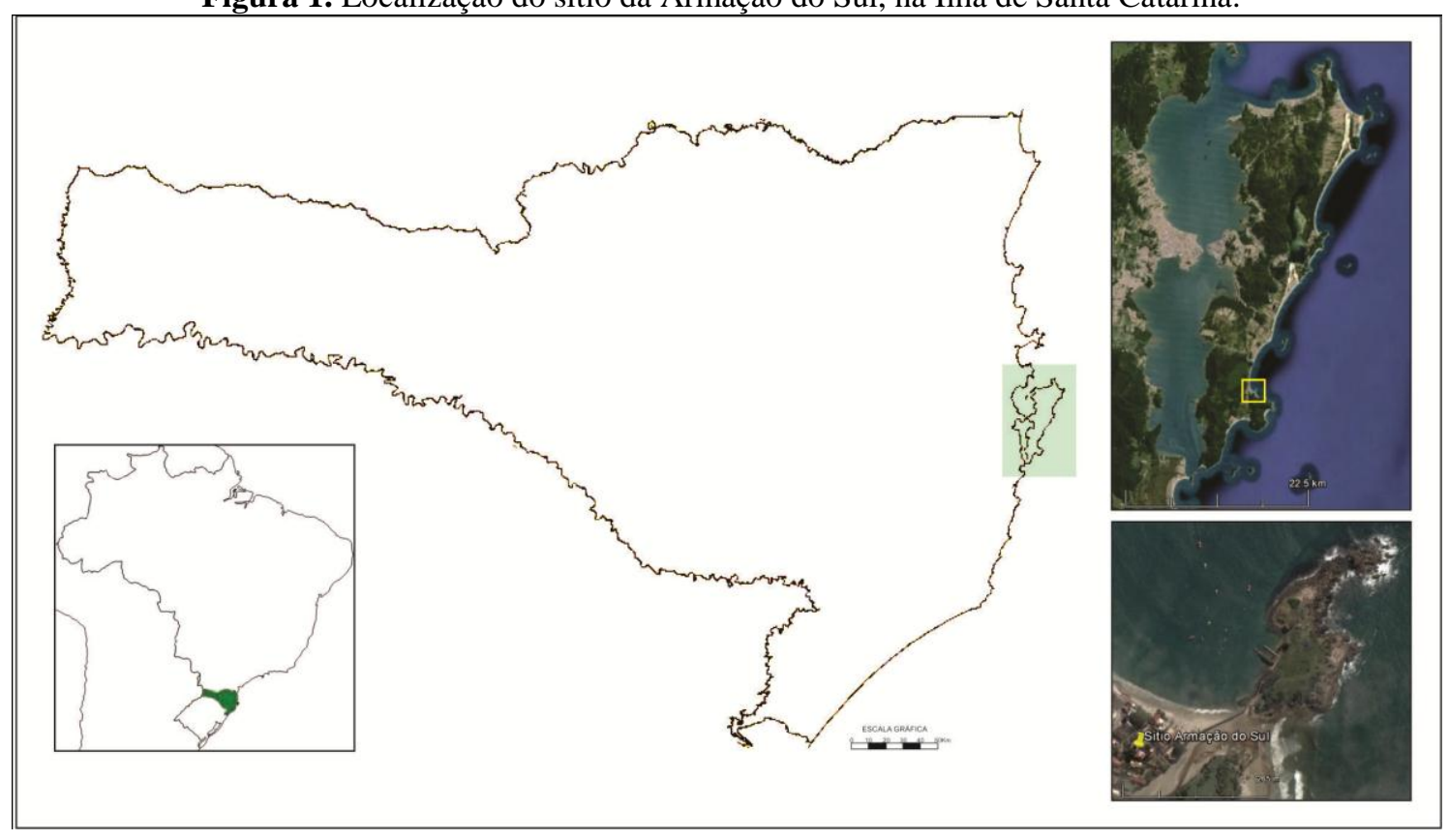

A partir de uma amostra de carvão coletada da camada mais profunda na etapa de 1969, o sítio da Armação do Sul foi datado em 2.670 +-90 A.P. (I-9212), data esta que possivelmente corresponde ao início da ocupação (SCHMITZ et al., 1992, p. 27).

Este sítio apresenta características ambíguas que dificultam sua classificação dentro das categorias de sítios litorâneos que habitualmente são utilizadas. Ele não é o que costumeiramente se denomina sambaqui, devido a pouca quantidade de conchas e pequena espessura da camada arqueológica e, embora se assemelhe a sítios conchíferos rasos como Tapera e Base Aérea, tampouco se enquadra junto a eles, uma vez que não apresenta cerâmica.

Com uma extensão total estimada em $1.200 \mathrm{~m}^{2}$, o sítio da Armação do Sul teve $269 \mathrm{~m}^{2}$ escavados $-85 \mathrm{~m}^{2}$ na primeira etapa e $184 \mathrm{~m}^{2}$ na segunda - sendo atingidos $2 \mathrm{~m}$ de profundidade e revelada estratigrafia semelhante para as áreas escavadas nas diferentes etapas: 1) Camada de húmus e raízes; 2) Camada de ocorrência de caliça, pedras e entulho de antiga estrutura de Armação baleeira; 3) Camada de húmus e fragmentos de material sub-recente; 4) Camada entre 50 e $80 \mathrm{~cm}$, descrita como de terra preta com areia, compacta, com conchas e grandes lentes de conchas - apresenta-se menos espessa na área escavada da segunda etapa; 5) Camada entre 80 e $110 \mathrm{~cm}$, composta por areias de cor marrom escura com terra; 6) Camada entre 110 e $190 \mathrm{~cm}$, composta por areias de cor marrom clara; 7) Camada a partir de $190 \mathrm{~cm}$, de areias de cor marrom clara, que 
formam a base do sítio (ROHR, 1969, p. 136; SCHMITZ et al., 1992, p. 25-27).

A impressão de descontinuidade que a estratigrafia do sítio pode evocar, passando de areia marrom para terra preta, é acompanhada por aparente descontinuidade nas práticas mortuárias relacionadas aos 86 sepultamentos escavados - embora, de acordo com Schmitz et al. (1992, p. 169), o mesmo não aconteça com relação à tecnologia lítica e óssea - tornando possível vislumbrar dois momentos diferentes na ocupação pré-colonial do sítio da Armação do Sul.

O primeiro deles estaria associado aos horizontes de areia marrom escura e areia marrom clara, sendo estratigraficamente mais antigo e com presença de sepultamentos em toda a extensão da área escavada, estes envoltos em pigmentos vermelhos e abundantemente acompanhados de adornos e outros artefatos. O segundo momento estaria associado ao horizonte de terra preta, sendo estratigraficamente mais recente e com os 19 sepultamentos que o compõem situados numa área mais restrita, estes sem presença de pigmentos vermelhos e raramente acompanhados de adornos ou qualquer artefato inteiro, com exceção de abundantes pontas ósseas. Estas últimas ocorrem ao longo de toda a estratigrafia do sítio, porém, sua associação aos sepultamentos é uma característica exclusiva do horizonte de terra preta (SCHMITZ et al., 1992, p. 151-152).

Schmitz et al. (1992, p. 155) interpretam esta mudança nos contextos funerários como um possível aumento dos conflitos e consequente valorização de chefes guerreiros, o que poderia estar atrelado à movimentação de populações ao longo do litoral ou do planalto para o litoral, sendo bastante representativo o caso de um indivíduo que estava acompanhado de 50 pontas ósseas junto à cabeça, estratigraficamente situado na transição entre os diferentes momentos do sítio. Esta ideia é reforçada por Lessa e Scherer (2008, p. 91-92) que, em análise da série esquelética do sítio em questão, identificaram um indivíduo masculino adulto cuja quarta vértebra lombar apresentava uma ponta óssea dentro do corpo vertebral, sem sinais de cicatrização ao redor da lesão. Até o momento, este é o único dado disponível sobre violência em sítios conchíferos sem cerâmica, ocorrência antes conhecida somente para sítios com cerâmica: Tapera e Base Aérea, no litoral central; Itacoara e Enseada I, no litoral norte (LESSA; SCHERER, 2008, p. 93-94). 


\section{APLICAÇÃO DE ISÓTOPOS DE ESTRÔNCIO NA ARQUEOLOGIA}

O estudo de isótopos de variados elementos vem revelando importantes ferramentas para a obtenção de informações em pesquisas arqueológicas (GOFFER, 2007, p. 39). Enquanto isótopos radioativos como ${ }^{14} \mathrm{C}$ e ${ }^{40} \mathrm{Ar}$ vêm fornecendo datações absolutas para a Arqueologia, a variação nas razões isotópicas de elementos estáveis como $\mathrm{H}, \mathrm{C}, \mathrm{O}, \mathrm{N}, \mathrm{S}, \mathrm{Sr}$, e $\mathrm{Pb}$ tem auxiliado na resolução de problemas de proveniência, paleoambientes e paleodietas (HERZ; GARRISON, 1998, p. 271).

Quando se trata de caracterizar mobilidade humana e animal são os isótopos de estrôncio que figuram entre os mais eficazes (BENTLEY, 2006, p. 135) e vêm gerando resultados interessantes (BENTLEY; KRAUSE; PRICE, 2003; KNUDSON et al., 2004; WRIGHT, 2005). O elemento estrôncio ( $\mathrm{Sr}$ ) possui quatro isótopos que ocorrem naturalmente, ${ }^{84} \mathrm{Sr}(0.56 \%),{ }^{86} \mathrm{Sr}(9.87 \%)$ e ${ }^{88} \mathrm{Sr}(82.53 \%)$, sendo o quarto deles, ${ }^{87} \mathrm{Sr}$ (7.04\%), um isótopo radiogênico, ou seja, fruto do decaimento radioativo de um radioisótopo mãe, no caso, do rubídio $\left({ }^{87} \mathrm{Rb}\right)$, que leva uma meia-vida de $4.88 \times 10^{10}$ anos para decair em ${ }^{87} \mathrm{Sr}$. Uma vez que depende do decaimento do ${ }^{87} \mathrm{Rb}$, a abundância de ${ }^{87} \mathrm{Sr}$ na geologia local é variável e determinada em relação a um isótopo de estrôncio não-radiogênico, o ${ }^{86} \mathrm{Sr}$. Esta variação, portanto, é chamada de "razão isotópica de estrôncio" $\left({ }^{87} \mathrm{Sr} /{ }^{86} \mathrm{Sr}\right)$, a qual depende da abundância de estrôncio, de rubídio - o que pode variar conforme o tipo de rocha - e da idade da rocha. Assim, unidades geológicas mais antigas e com alta concentração de rubídio, apresentarão razões isotópicas ${ }^{87} \mathrm{Sr} /{ }^{86} \mathrm{Sr}$ mais elevadas, ao passo que formações geológicas mais recentes e com baixa concentração de rubídio, apresentarão razões isotópicas menores (BENTLEY, 2006, p. 137; PRICE; BURTON; BENTLEY, 2002, p. 118).

Por meio da erosão dos materiais geológicos, o estrôncio presente nas rochas atinge o solo e a água subterrânea, caminho que o leva até a cadeia alimentar e, portanto, ao esqueleto humano, onde substitui o cálcio nos minerais do tecido esquelético (BENTLEY, 2006, p. 136). Embora a concentração de estrôncio total nos tecidos das plantas e animais possa sofrer variação, a composição isotópica de estrôncio não é modificada por processos biológicos, fazendo com que a composição de isótopos de estrôncio nos ossos e dentes corresponda à da dieta do indivíduo e esta, por sua vez, reflita a assinatura isotópica ${ }^{87} \mathrm{Sr} /{ }^{86} \mathrm{Sr}$ da geologia local. Deste modo, a análise de 
isótopos de estrôncio em indivíduos sepultados revela a razão isotópica do estrôncio consumido que, se comparada à razão isotópica da geologia local, pode gerar informações sobre migração e mobilidade humana pré-colonial (PRICE; BURTON; BENTLEY, 2002, p. 118).

Ossos e dentes (dentina), no entanto, são muito suscetíveis a contaminações pósdeposicionais, causadas por processos diagenéticos que podem modificar a assinatura isotópica outrora presente no esqueleto do indivíduo em vida (HILLSON, 2005, p. 152). Por esta razão, muitos estudos de mobilidade humana a partir de ${ }^{87} \mathrm{Sr} /{ }^{86} \mathrm{Sr}$ têm focado exclusivamente no esmalte dentário para a realização das análises (BENTLEY, 2006, p. 169). O esmalte dentário costuma ser, dentre os tecidos duros, aquele que melhor se preserva: sua composição predominantemente mineral (menos de $1 \%$ de matéria orgânica) faz com que a decomposição da matéria orgânica do indivíduo sepultado tenha mínimos efeitos sobre o esmalte e, ainda, sua natureza cristalina faz dele duro e forte, resistente à erosão mecânica, possibilitando alcançar resultados mais confiáveis (HILLSON, 2005, p. 158). Além disso, diferentemente dos ossos, o esmalte dentário não sofre remodelação, sendo formado na infância e permanecendo igual, com mínima alteração, ao longo da vida (HILLSON, 2005, p. 153), o que permite a análise da assinatura isotópica do estrôncio consumido nos primeiros anos de vida do indivíduo. Nesse caso, se a razão isotópica do esmalte apresentar-se semelhante à da geologia local, o indivíduo possivelmente será de proveniência local e, se a razão apresentar-se diferente, o indivíduo possivelmente será um imigrante (não-local), tendo vivido em outra região durante a infância.

No Brasil, análises de isótopos de estrôncio foram realizadas por Bastos (2009, 2014) e Calippo (2010), porém com enfoques diferentes. Bastos $(2009,2014)$ estudou, respectivamente, o sítio do Forte Marechal Luz, em São Francisco do Sul, e o sítio da Tapera, em Florianópolis, com o objetivo de investigar padrões de mobilidade e migração humana a partir da correlação entre as razões isotópicas de estrôncio presentes nos esmaltes dentários e aquelas disponíveis na geologia e biologia local. Calippo (2010), por sua vez, buscou investigar a relação existente entre diferentes agrupamentos de sambaquis situados no médio vale do Ribeira, baixo vale do Ribeira, litoral central e litoral norte de São Paulo, a partir da comparação entre as razões isotópicas médias dos indivíduos de cada um dos conjuntos de sítios. $\mathrm{O}$ enfoque da pesquisa apresentada aqui 
se assemelha àquele de Bastos $(2009,2014)$.

\section{MATERIAIS E MÉTODOS}

Para a análise da razão isotópica de estrôncio presente no esmalte dentário dos indivíduos sepultados no sítio conchífero da Armação do Sul foram selecionados todos os indivíduos presentes na reserva técnica do Museu do Homem do Sambaqui "Pe. João Alfredo Rohr, S.J." que possuíam mandíbula e/ou maxila, que apresentavam esmalte dentário e sobre os quais se tinha as informações arqueológicas necessárias para contextualização. Ou seja, o critério de seleção foi o mais amplo possível, pautando-se somente nos requisitos indispensáveis ao pleno desenvolvimento das análises. Alguns casos isolados, mesmo atendendo a este critério, foram excluídos por apresentarem sedimento concrecionado no entorno do crânio, o que impediu a coleta do dente ${ }^{6}$.

Houve preferência pelos dentes pré-molares, que sofrem mineralização entre 2 e 7 anos de idade (HILSSON, 2005), mas na ausência dos dentes visados, ou nos casos em que estes não apresentavam esmalte suficiente para a análise, foram coletados segundos ou terceiros molares, que mineralizam na idade de 3 a 8 anos e 9 a 14 anos, respectivamente. Evitamos a coleta de dentes com presença de patologias ou desgaste diferenciado, uma vez que poderão vir a gerar informações importantes a outras pesquisas.

Juntamente com os dentes humanos, foram selecionados dentes de fauna terrestre e marinha do sítio da Armação do Sul, de modo a determinar a assinatura isotópica ${ }^{87} \mathrm{Sr} /{ }^{86} \mathrm{Sr}$ biologicamente disponível no local e compará-la à assinatura do esmalte dentário humano (BENTLEY, 2006, p. 136). Foram também selecionadas conchas de ambiente estuarino e de mar aberto, de forma a verificar se há diferença entre assinatura de estrôncio desses dois ambientes.

No total, foram selecionados 39 dentes humanos para a análise, pertencentes a indivíduos adultos e subadultos, nove dentes de fauna terrestre, um dente de fauna marinha, uma concha de ambiente estuarino e uma concha de mar aberto. O sexo e a idade dos indivíduos foram determinados segundo o protocolo de Buikstra e Ubelaker (1994). Todo o material coletado foi devidamente fotografado e documentado.

\footnotetext{
${ }^{6}$ As coletas foram realizadas com o auxílio da bioarqueóloga Me. Luciane Zanenga Scherer.
} 
Os dentes passaram por um processo de limpeza mecânica e química de modo a retirar possíveis contaminantes pós-deposicionais - como carbonatos - aderidas aos dentes, conforme sugerido por diversos autores (BENTLEY et al., 2003; KNUDSON et al., 2004; WRIGHT, 2005) e seguindo o protocolo de Bastos (2009). Os dentes foram higienizados com o uso de água deionizada, sendo a superfície do esmalte escovada com escova de dente, raspada com sonda exploratória de dentista e, também, com bisturi n. 12 nos casos de incrustações mais difíceis de retirar. Em seguida, no espaço do laboratório limpo do Centro de Pesquisas Geocronológicas (CPGeo/USP), os dentes foram imersos em ácido acético $0,5 \mathrm{M}$ e colocados em ultrassom por $20 \mathrm{~min}$, para depois serem enxaguados com água deionizada e deixados a secar $^{7}$.

Foram retiradas em torno de $20 \mathrm{mg}$ de esmalte de uma das superfícies laterais de cada dente com broca diamantada esférica PM6 e PM7 (marcas Fava a KG Sorensen), etapa que foi realizada no Laboratório de Sistemas Cársticos (USP). Dos dentes que apresentavam quantidade menor de esmalte foram retiradas amostras também menores, tendo o caso mais extremo chegado a somente $3,9 \mathrm{mg}$, sem causar problemas posteriores na leitura do sinal pelo espectrômetro. Para as conchas seguimos o mesmo procedimento dos dentes, porém ignoramos a primeira raspada com a broca, uma vez que elas não foram previamente limpas.

De volta ao laboratório limpo, as amostras pulverizadas foram pesadas e transferidas para tubos Savillex, onde sofreram um tratamento químico que consistiu na adição de $2 \mathrm{ml}$ de HNO3 concentrado, em meio ao qual foram digeridas por $1 \mathrm{~h}$. Em seguida foram colocadas para secar sobre a chapa quente. As amostras relativas às conchas, receberam um tratamento diferente, sendo atacadas com $1 \mathrm{ml}$ de HCL e colocadas para secar logo depois. Uma vez secas, todas as amostras foram dissolvidas em $1 \mathrm{ml}$ de HNO3 2M para passagem na coluna de troca iônica preenchida com $\sim 1 \mathrm{~cm}$ de resina Sr-Spec, onde foram purificadas segundo o protocolo do CPGeo/USP.

A composição isotópica das amostras foi determinada por um Espectrômetro de Massas de Termoionização (TIMS) TRITON. O controle de branco de $\mathrm{Sr}$ durante as análises variou entre 108 e $166 \mathrm{pg}$. As razões isotópicas ${ }^{87} \mathrm{Sr} /{ }^{86} \mathrm{Sr}$ foram normalizadas para o valor de ${ }^{87} \mathrm{Sr} /{ }^{86} \mathrm{Sr}=0,1194$. Ao longo dos sete meses em que foram realizadas as

\footnotetext{
${ }^{7}$ As etapas de limpeza e retirada do esmalte foram realizadas com o auxílio do Dr. Murilo Quintans Bastos e apoio técnico da equipe do CPGeo/USP.
} 
análises, de janeiro a julho de 2014, o valor médio para a razão ${ }^{87} \mathrm{Sr} /{ }^{86} \mathrm{Sr}$ do padrão NBS-987 variou entre $0.710236 \pm 0.000020$ e $0.710251 \pm 0.000038$.

\section{RESULTADOS PARCIAIS E DISCUSSÃO INICIAL}

Embora todas as amostras selecionadas para análise de isótopos de estrôncio já tenham sido preparadas, tendo passado pelas etapas de limpeza e de tratamento químico, os resultados apresentados a seguir são parciais, referentes a apenas 23 indivíduos humanos (59\% da amostra total). As demais amostras humanas, bem como as amostras faunísticas, encontram-se aguardando na fila para a leitura no espectrômetro de massas.

Os valores da razão ${ }^{87} \mathrm{Sr} /{ }^{86} \mathrm{Sr}$ dos 23 indivíduos já analisados variaram entre 0,70950 e 0,71097, apresentando média de 0,71006 com desvio padrão de 0,00039.

Figura 2. Gráfico de dispersão dos valores de ${ }^{87} \mathrm{Sr} /{ }^{86} \mathrm{Sr}$ dos indivíduos analisados do sítio da Armação do Sul.

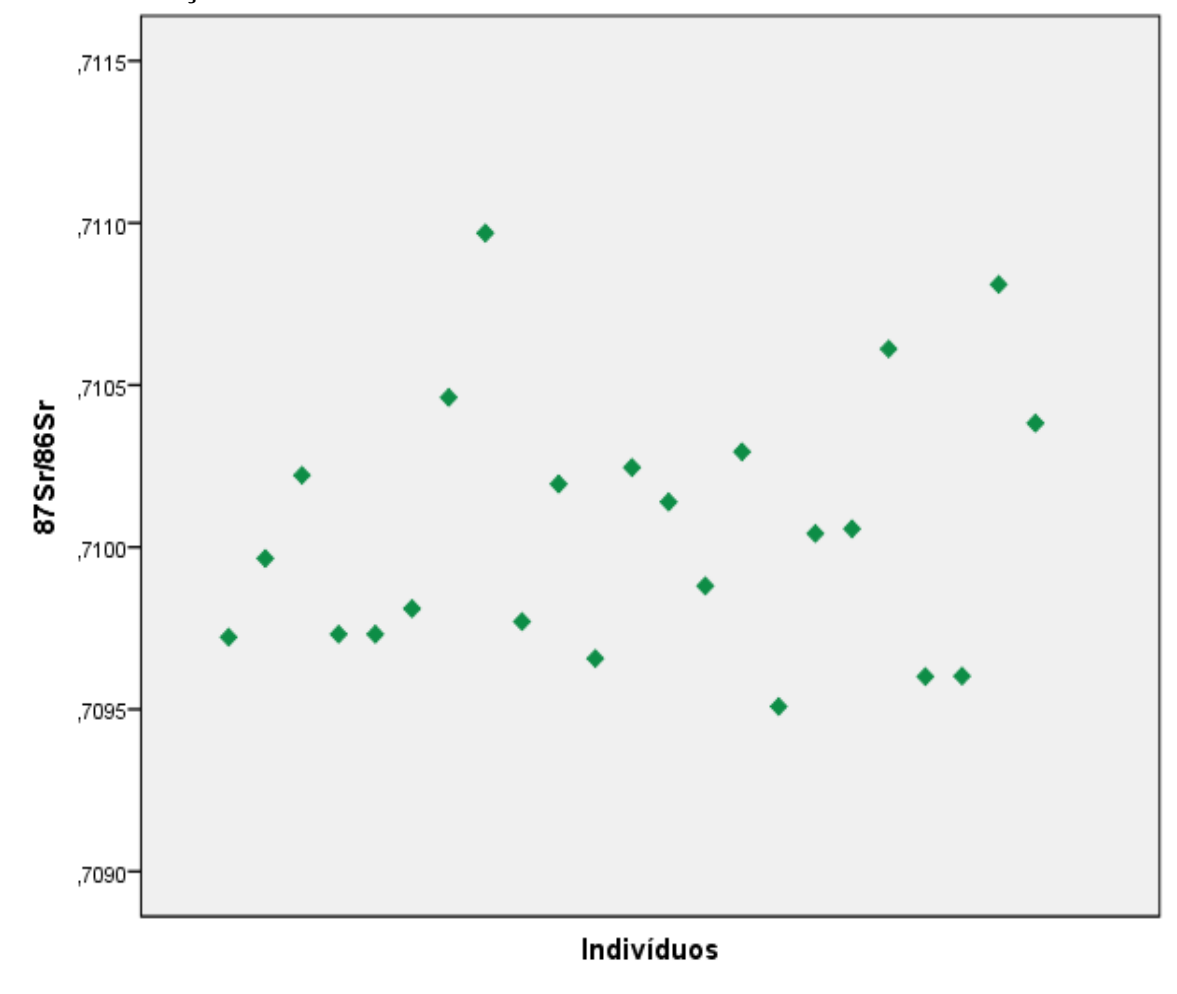

Como as amostras faunísticas ainda não foram analisadas, não é possível observar se as assinaturas isotópicas humanas se encontram dentro da faixa de variação determinada pelas assinaturas isotópicas biologicamente disponíveis e, portanto, não 
podemos inferir com exatidão a presença ou ausência de indivíduos não-locais no sítio da Armação do Sul, provenientes de lugares que apresentem outra disponibilidade isotópica.

Sabemos, no entanto, que a razão ${ }^{87} \mathrm{Sr} /{ }^{86} \mathrm{Sr}$ dos oceanos atuais é de 0,7092 (WRIGHT, 2004), e, comparando os resultados do sítio da Armação do Sul com os resultados obtidos por Bastos (2014) para o sítio da Tapera, também situado no sul da ilha de Santa Catarina e no qual as razões obtidas para os indivíduos foram compatíveis com os valores obtidos para a fauna local, é possível trabalhar com a ideia de que os indivíduos no sítio da Armação do Sul também devem apresentar essa compatibilidade e, logo, serem locais. Isso porque a geologia da área onde estes sítios estão implantados é semelhante, assim como a fauna arqueológica neles encontrada, que deve, portanto, apresentar uma faixa de variação isotópica também semelhante.

Disponibilidade biológica à parte, a ausência de outliers entre os valores ${ }^{87} \mathrm{Sr} /{ }^{86} \mathrm{Sr}$ obtidos até o momento, por si só, já aponta para a possibilidade de todos os indivíduos analisados serem locais.

Figura 3. Boxplot representando as razões ${ }^{87} \mathrm{Sr} /{ }^{86} \mathrm{Sr}$ dos indivíduos analisados do sítio da Armação do Sul.

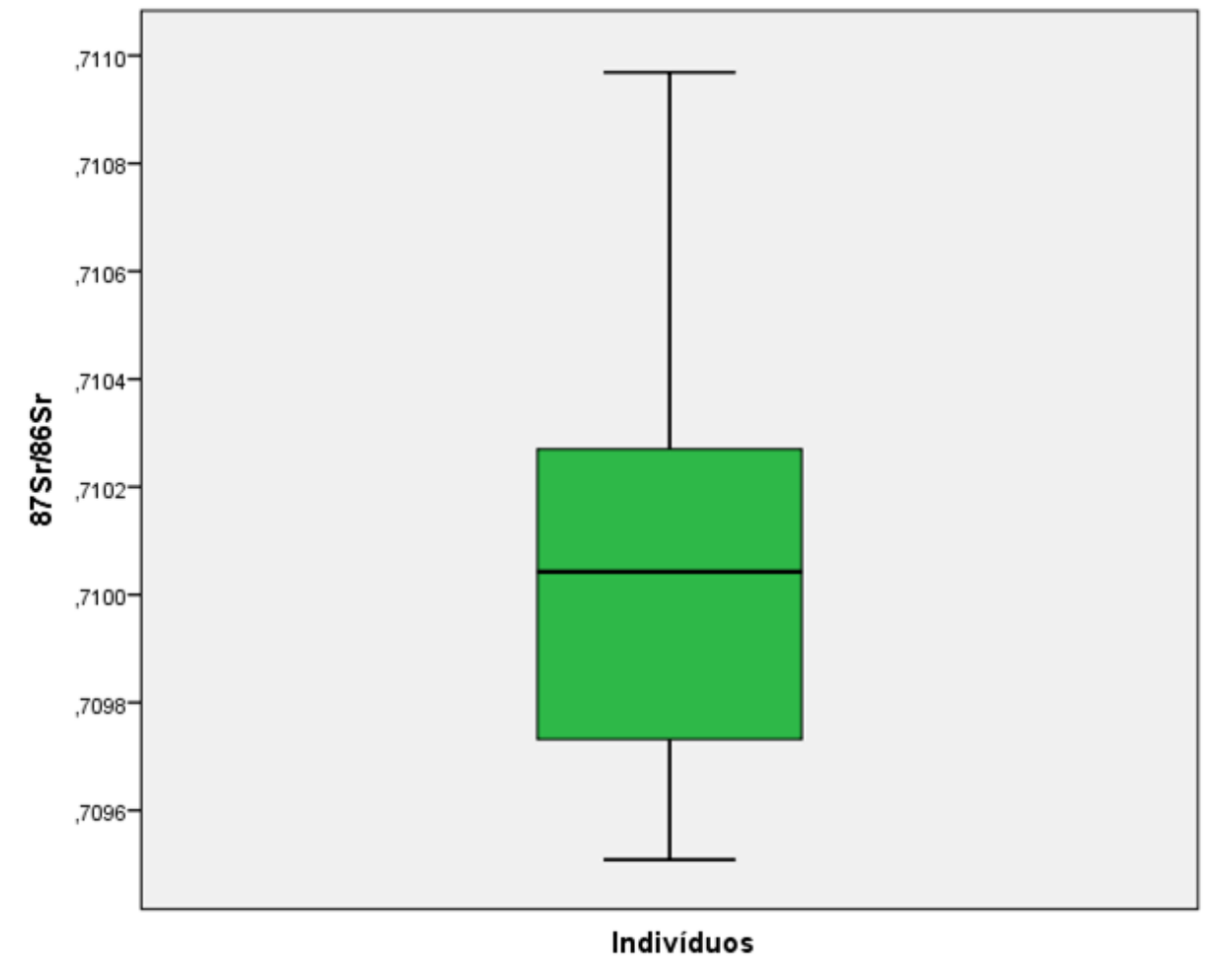


É importante atentarmos, contudo, para o fato de que apesar de não haverem outliers entre os indivíduos analisados, suas assinaturas isotópicas estão distribuídas numa larga faixa de variação, com uma amplitude de 0,00146 e com 50\% dos casos concentrando-se entre 0,7097 e 0,7103, como é possível observar no boxplot acima. É possível que a presença de indivíduos provenientes de outras porções do litoral catarinense que apresentem disponibilidade isotópica parecida com a do litoral central sejam responsáveis por essa variação, estando misturados àqueles que são de fato locais. Essa hipótese foi levantada por Bastos (2014) para as mulheres do sítio da Tapera, uma vez que elas apresentaram uma maior variação em seus valores do que os homens.

Figura 4. Boxplot das razões isotópicas de ${ }^{87} \mathrm{Sr} /{ }^{86} \mathrm{Sr}$ dos indivíduos do sexo feminino e masculino do sítio da Armação do Sul.

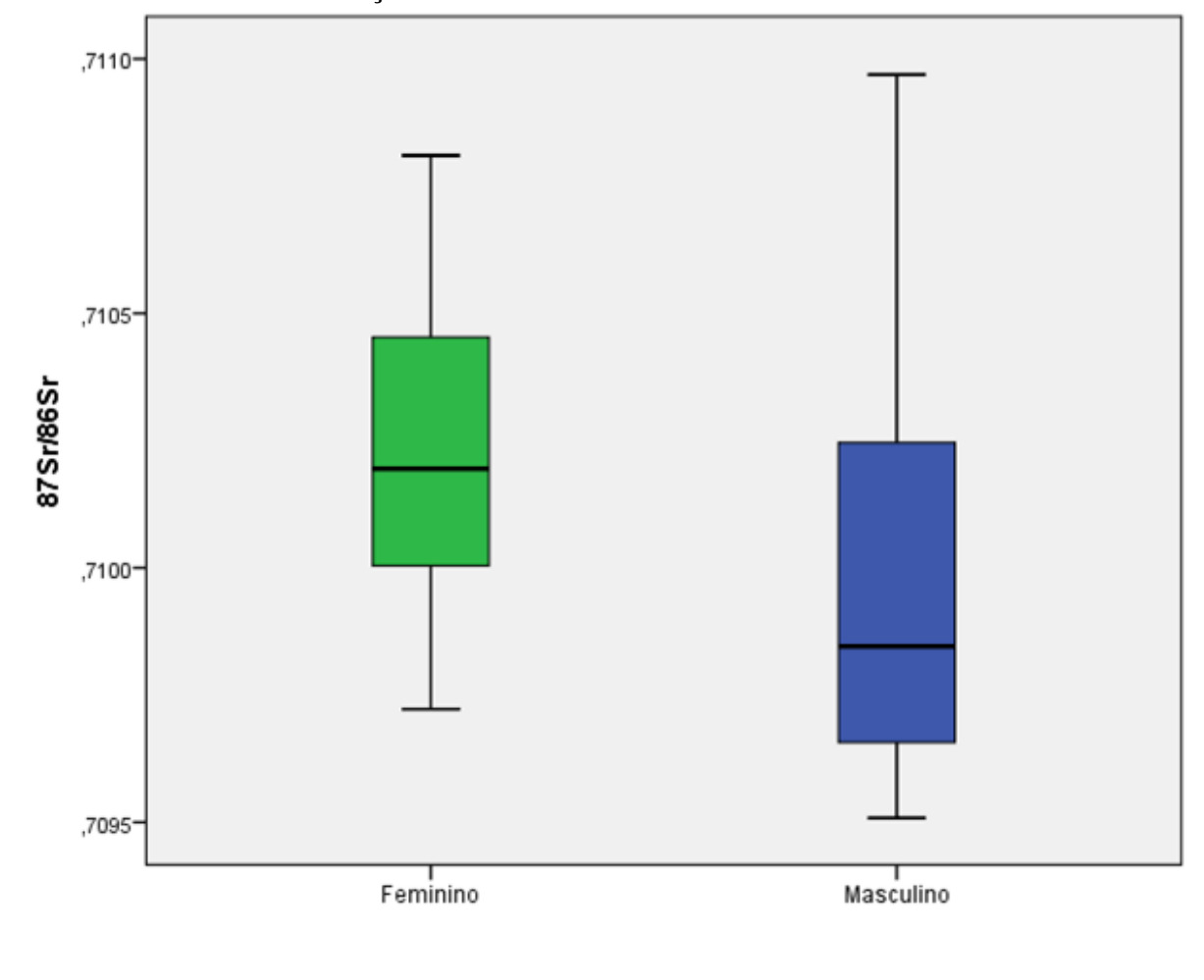

Como já mencionado, os indivíduos do sexo feminino do sítio da Tapera apresentaram uma maior variação nas razões isotópicas que os indivíduos do sexo masculino (BASTOS, 2014), o que vai ao encontro da ideia de mudança para um padrão de residência virilocal em tempos mais tardios, conforme sugerido por Hubbe et al. (2009). No sítio da Armação do Sul, os resultados que temos até o momento apontam na direção contrária, com os indivíduos masculinos apresentando uma maior variação que 
os indivíduos do sexo feminino. Estes, contudo, são dados preliminares correspondentes a apenas $59 \%$ da amostra - e não significativos para um nível de confiança de $95 \%(\mathrm{P}>0,05)$.

Figura 5. Boxplot das razões isotópicas ${ }^{87} \mathrm{Sr} /{ }^{86} \mathrm{Sr}$ dos indivíduos situados na camada de terra preta e dos indivíduos situados na camada de areia marrom do sítio da Armação do Sul.

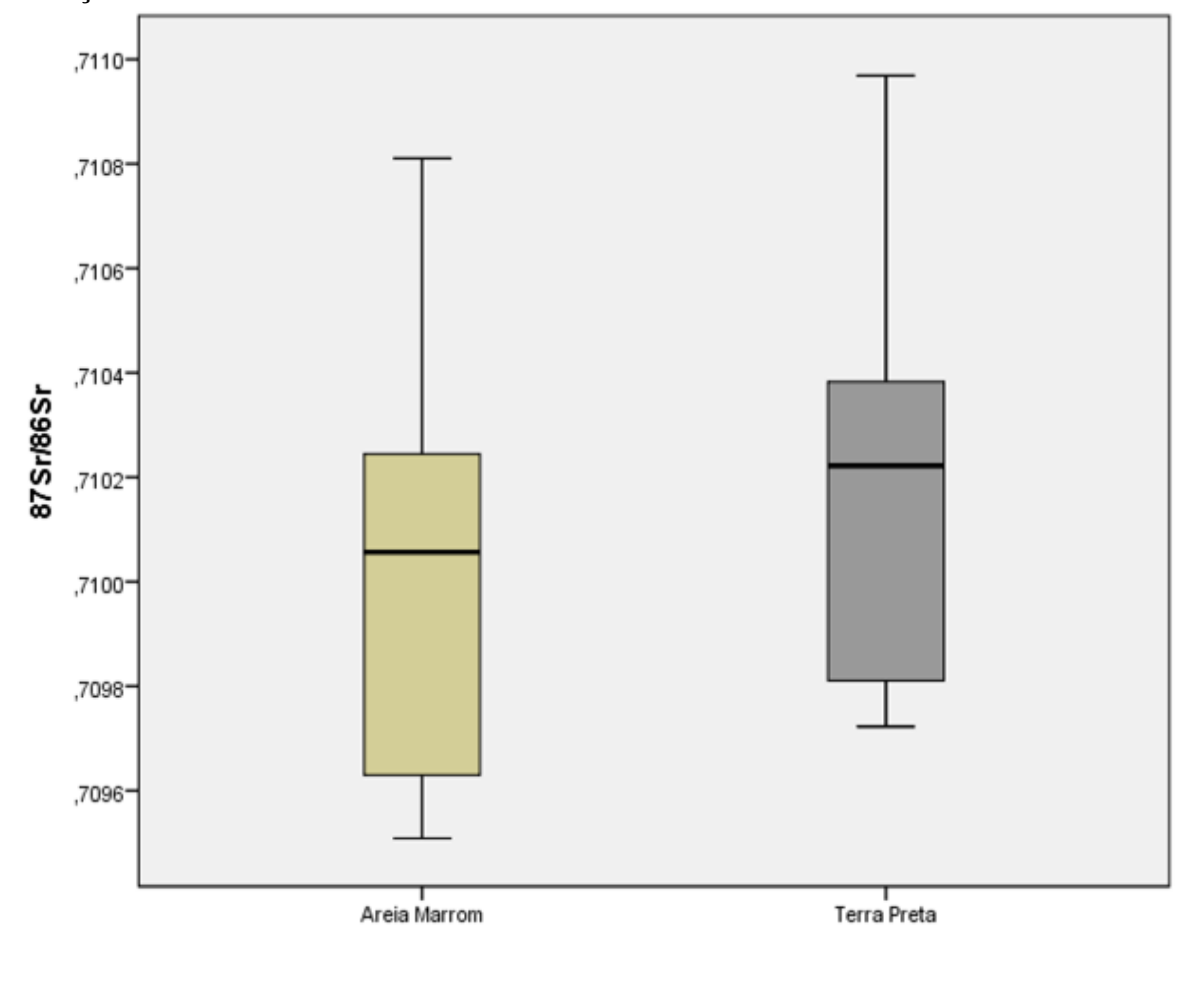

A diferença encontrada entre as razões isotópicas dos indivíduos situados na terra preta, que são maiores, e dos indivíduos situados na camada de areia marrom, que são menores, também não é significativa para um nível de confiança de 95\% ( $\mathrm{P}>0,05)$, além de ser baseada em dados parciais, mas pode estar apontando para o início da mudança - essa, sim, significativa - que percebemos do sítio da Armação do Sul para o sítio da Tapera. Essa mudança é observável no gráfico abaixo. 
Figura 6. Gráfico de dispersão dos valores de ${ }^{87} \mathrm{Sr} /{ }^{86} \mathrm{Sr}$ dos indivíduos analisados dos sítios Tapera (BASTOS, 2014), Forte Marechal Luz (BASTOS, 2009) e Armação do Sul.

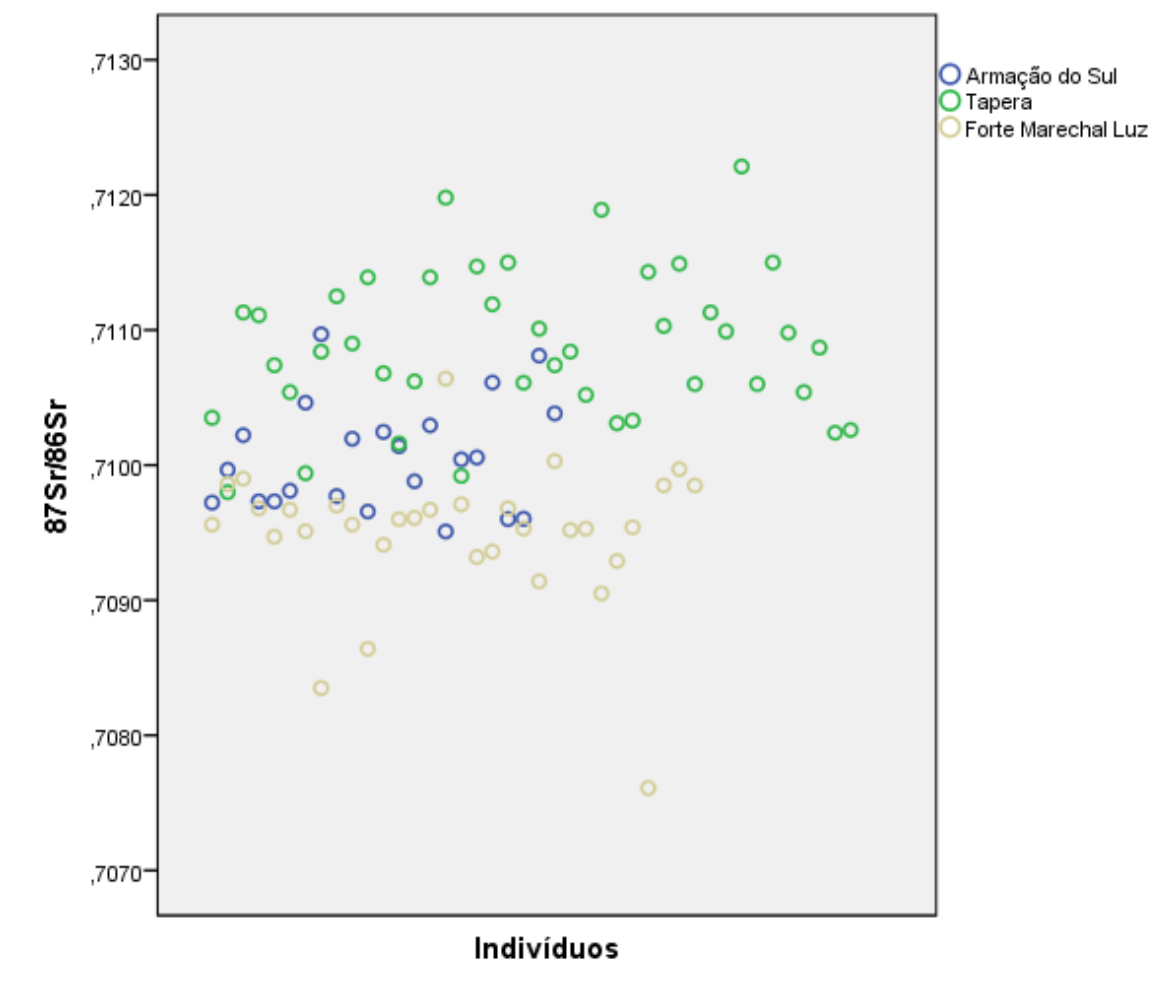

Embora apresentem um padrão semelhante, com razões distribuídas numa larga faixa de variação, os sítios da Armação do Sul e da Tapera apresentam diferença significativa para um nível de confiança de $95 \%(\mathrm{P}=0,05)$ na média dos valores dessas razões, sendo possível observar valores mais elevados no sítio da Tapera.

Armação do Sul (2.670 +-90 A.P.) e Tapera (1.140 \pm 180 AP) representam momentos diferentes da ocupação do litoral, logo, é possível dizer que houve uma mudança significativa na assinatura isotópica média da população do litoral central por volta de 1.000 A.P. Mudança esta que possivelmente já vinha se prenunciando desde tempos anteriores, período em que os indivíduos do sítio da Armação do Sul passaram a ser sepultados em meio à terra preta.

Outra diferença significativa $(\mathrm{P}=0,05)$ evidenciada pelo diagrama de dispersão é entre as médias das razões isotópicas apresentadas pelo sítio do litoral norte (Forte Marechal Luz) e os sítios do litoral central (Tapera e Armação). A média dos valores isotópicos dos indivíduos do forte Marechal Luz é menor que as médias dos valores dos outros dois sítios, o que se explica pela formação geológica mais recente que caracteriza o litoral norte se comparada à do litoral central, o que já havia sido observado por 
Bastos (2014) para explicar as diferença entre Forte Marechal Luz e Tapera, sítios por ele estudados.

Figura 7. Mapa geológico do Estado de Santa Catarina. Fonte: Silva e Bortoluzzi (1987).

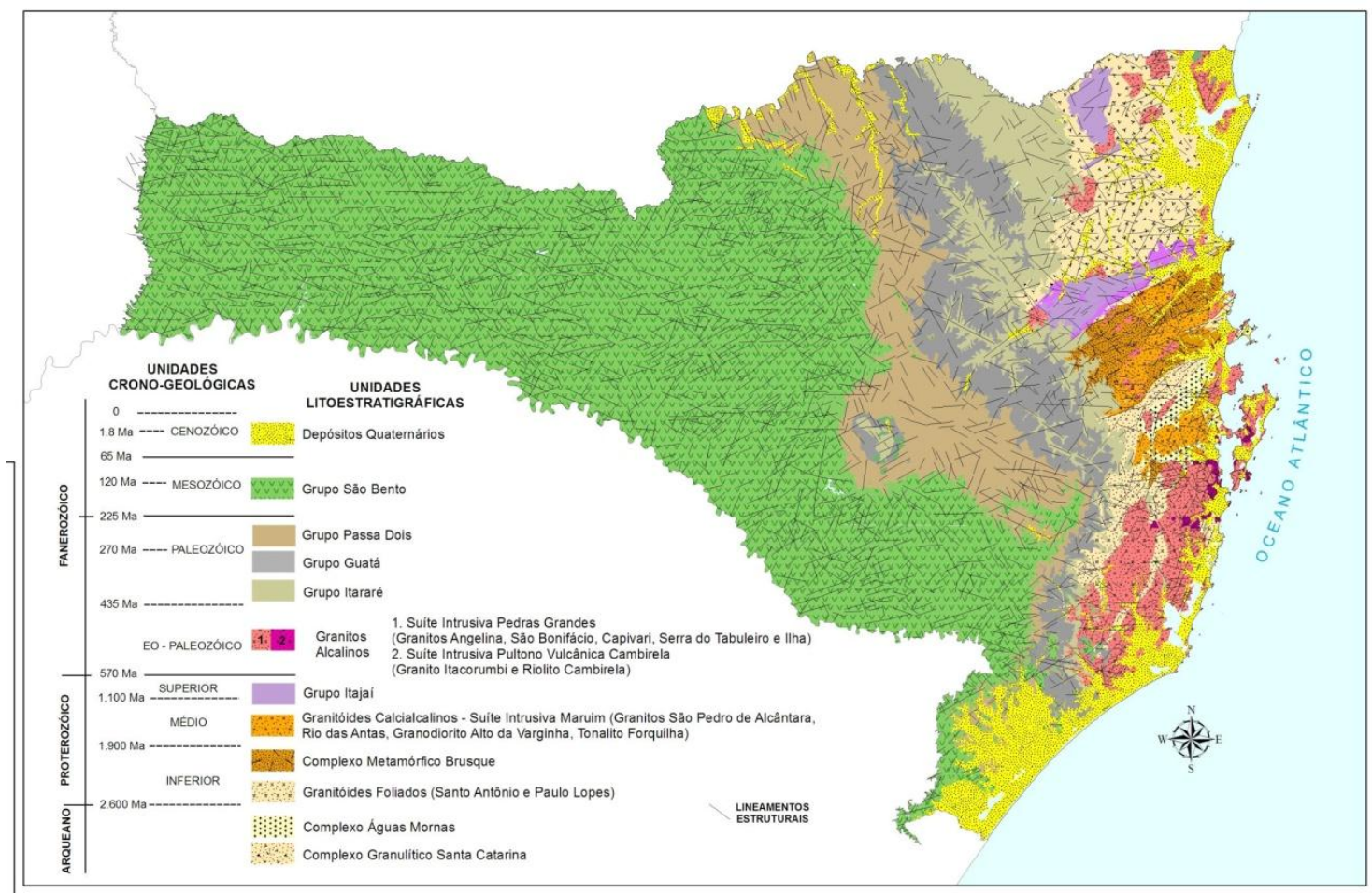

O reconhecimento dessa diferença entre os valores do litoral norte e central nos dá um maior poder interpretativo frente aos dados, mostrando que indivíduos provenientes do litoral norte podem vir a ser identificados quando estiverem sepultados em sítios do litoral central e vice-versa. Além disso, mostra que os isótopos de estrôncio são um caminho possível para a melhor compreensão das relações estabelecidas fluxos de ideias, objetos e pessoas - entre as populações das diferentes porções do litoral catarinense, e não somente das relações estabelecidas com o interior e outras regiões litorâneas mais distantes. 
Figura 8: Boxplot das razões ${ }^{87} \mathrm{Sr} /{ }^{86} \mathrm{Sr}$ dos indivíduos do sexo feminino e masculino do sítio Armação do Sul, Tapera (BASTOS, 2014) e Forte Marechal Luz (BASTOS, 2009).

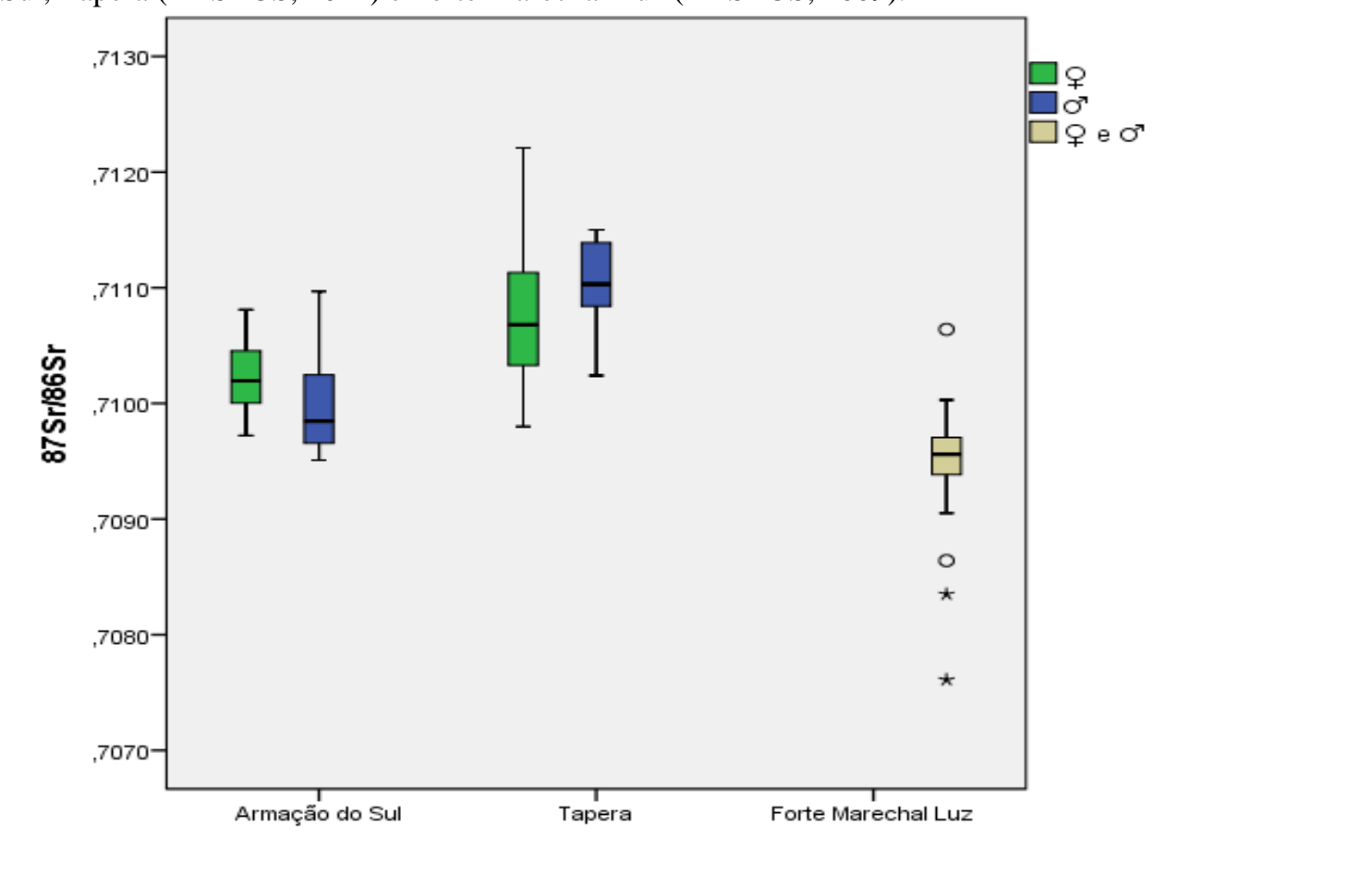

A formação geológica, contudo, não explica a maior variação das razões obtidas para os sítios Tapera e Armação do Sul - com coeficientes de variação de Pearson $(\mathrm{CVp})$ de 0,078\% e 0,056\% respectivamente - frente à estreita variação do Forte Marechal Luz - com CVp de 0,033\%. Também não explica a maior variação do sítio Tapera frente ao sítio Armação do Sul.

Essa diferença nas variações pode estar relacionada a uma maior circulação de indivíduos provenientes de áreas próximas com formação geológica distinta ao longo do litoral central em tempos mais tardios. Nesse caso, os indivíduos dos sítios Armação do Sul e Tapera que apresentam assinaturas isotópicas mais elevadas poderiam ser provenientes de áreas geologicamente mais antigas do litoral central - como as regiões de Porto Belo ou Balneário Camboriú, que remetem ao Arqueano - tendo sido incorporados pelas populações desses sítios. Nada pode ser afirmado nesse sentido, contudo, enquanto novos estudos isotópicos ao longo do litoral catarinense não forem realizados. 


\section{CONSIDERAÇÕES FINAIS}

As análises isotópicas de estrôncio realizadas nos indivíduos sepultados no sítio Armação do Sul mostraram que as mudanças observadas ao longo da estratigrafia do sítio provavelmente não estão relacionadas à incorporação de indivíduos não-locais provenientes do planalto ou de regiões litorâneas distantes de formação geológica mais recente, mesmo resultado obtido por Bastos (2014) com relação a presença de cerâmica no sítio Tapera. É possível, no entanto, que tais mudanças estejam relacionadas à incorporação de indivíduos provenientes de regiões litorâneas próximas, no litoral central, embora não seja prudente fazer afirmações nesse sentido antes que mais estudos sejam realizados para um melhor entendimento das pequenas variações isotópicas entre porções distintas do litoral catarinense.

A constatação de uma pequena diferença entre a média das assinaturas de ${ }^{87} \mathrm{Sr} /{ }^{86} \mathrm{Sr}$ do sítio Forte Marechal Luz (BASTOS, 2009), no litoral norte, e as médias dos sítios Tapera (BASTOS, 2014) e Armação do Sul, no litoral central, mostra que essa variação entre porções litorâneas próximas existe e que, portanto, com um aprofundamento dos estudos e mapeamento das variações, os isótopos de estrôncio poderão passar a informar não apenas sobre as relações estabelecidas com populações do interior e outras regiões litorâneas mais distantes, mas também sobre as relações estabelecidas - troca de ideias, objetos e pessoas - entre as populações das diferentes porções do litoral catarinense.

Ademais, os resultados contribuem para um melhor entendimento dos processos de mudança pelos quais passaram as populações do litoral catarinense a partir de 2.000 A.P., chamando atenção para a importância da relação entre indivíduo e estrutura nesses processos de mudança social e, logo, para a importância de entendê-los contextualmente. Os dados obtidos até o momento mostram que acontecimentos possivelmente semelhantes de ordem cultural e/ou ambiental - como a diminuição do nível do mar ou o contato intercultural - se desenrolaram diferentemente no litoral norte e no litoral central do Estado. A população do sítio Forte Marechal Luz (BASTOS, 2009) manteve o mesmo padrão de mobilidade após o aparecimento da cerâmica, com manutenção da média dos valores isotópicos e incorporação eventual de indivíduos de outras regiões litorâneas. A população da Tapera (BASTOS, 2014) também manteve o 
padrão de mobilidade observado na Armação do Sul, caracterizado por uma grande variação nos valores isotópicos, no entanto, apresentou valores ainda mais altos, elevando tanto a média dos valores quanto seu coeficiente de variação.

O que parece é que em meio às mudanças que estavam acontecendo, a população associada ao sítio Forte Marechal Luz manteve-se circunscrita em torno dela mesma, enquanto as populações da Armação do Sul e da Tapera tornaram-se ainda mais abertas do que eram, expandindo suas fronteiras - pelo menos no sentido de trocas de alimentos e/ou pessoas - para regiões litorâneas próximas com presença de formações geológicas mais antigas.

\section{REFERÊNCIAS}

BASTOS, M. Q. R.. Mobilidade humana no litoral brasileiro: análise de isótopos de estrôncio no sambaqui do Forte Marechal Luz. Dissertação (Mestrado em Ciências) Escola Nacional de Saúde Pública, Fundação Oswaldo Cruz, Rio de Janeiro, 2009.

BASTOS, M. Dos sambaquis do sul do Brasil à diáspora africana: estudos de geoquímica isotópica de séries esqueléticas humanas escavadas de sítios arqueológicos brasileiros. Tese (Doutorado em Geologia) - Universidade de Brasília, Brasília, 2014.

BENTLEY, R. A. Strontium isotopes from the Earth to the archaeological skeleton: a review. Journal of Archaeological Method and Theory, vol. 13, n. 3, p. 135-187, set. 2006.

BENTLEY, R. A.; KRAUSE, R.; PRICE, T. D. Human mobility at the early neolithic settlement of Vaihingen, Germany: evidence from strontium isotope analysis. Archaeometry, v. 45, n. 3, p. 471-486, 2003.

DEBLASIS, P.; KNEIP, A.; SCHEEL-YBERT, R.; GIANINNI, P.C.; GASPAR, M.D. Sambaquis e paisagem: dinâmica natural e Arqueologia regional no litoral do sul do Brasil. Revista Arqueología Suramericana, 3, p. 29-61, 2007.

DEBLASIS, P. \& GASPAR, M.D. Os sambaquis do sul Catarinense: retrospectiva e perspectiva de dez anos de pesquisas. Especiaria - Cadernos de Ciências Humanas, Ilhéus, 20/21 (11/12), p. 83-125, 2008/2009.

HILLSON, S. Teeth. New York: Cambridge University Press, 2005.

HUBBE, M.; NEVES, W.; OLIVEIRA, E.C.; STRAUSS, A. Postmarital residence practice in Southern Brazilian coastal groups: continuity and change. Latin American Antiquity, v. 20, n. 2, p. 1-12, 2009. 
KNUDSON, K. J; PRICE, T. D.; BUIKSTRA, J. E.; BLOM, D. E. The use of strontium isotope analysis to investigate Tiwanaku migration and mortuary ritual in Bolivia and Peru. Archaeometry, v. 46, n.1, p. 5-18, 2004.

LESSA, A.; SCHERER, L. Z. O outro lado do paraíso: novos dados e reflexões sobre violência entre pescadores-coletores pré-coloniais. Revista do Museu de Arqueologia e Etnologia, São Paulo, n. 18, p. 89-100, 2008.

PRICE, T. D.; BURTON, J. H.; BENTLEY, R. A. The characterization of biologically available strontium isotope ratios for the study of Prehistoric migration. Archaeometry, Great Britain, n. 44, p. 117-135, 2002.

ROHR, J. A. Armação do Sul: três mil anos de história. Correio do Povo, Porto Alegre, 21 abr. 1974.

ROHR, J. A.; ANDREATTA, M. O sítio arqueológico da Armação do Sul (nota prévia). In: Anais do Terceiro Simpósio de Arqueologia da Área do Prata. Pesquisas, Antropologia, n. 20, Estudos Leopoldenses, n. 13, 1969.

SCHMITZ, P. I.; DE MASI, M. A. N.; VERARDI, I.; LAVINA, R.; JACOBUS, A. L. O sítio arqueológico da Armação do Sul. Pesquisas, Antropologia, São Leopoldo, n. 48, 1992.

SILVA, L. C.; BORTOLUZZI, C. A. (Eds.). Mapa Geológico do Estado de Santa Catarina. DNPM/CODISC, Florianópolis. 1 mapa color. Escala 1:500.000. In: Série Textos Básicos de Geologia e Recursos Minerais de Santa Catarina, n. 1, 1987.

WRIGHT, L. E. Identifying immigrants to Tikal, Guatemala: defining local variability in strontium isotope ratios of human tooth enamel. Journal of Archaeological Science, 32, p. 555-566, 2005. 